\title{
La destrucción del bosque nativo en Chile
}

\author{
Roberto Cornejo Espósito
}

Presidente Nacional Colegio Ingenieros Forestales, San Isidro 22, oficina 503, Santiago de Chile, email: robertocornejoe@gmail.com

Se cree que la principal destrucción de nuestro bosque nativo, de alguna manera, es producto de sustitución de esos bosques, por especies de más rápido crecimiento, como el Pinus insignis D. Don y el Eucaliptus globulus Labill., así en este contexto, se entrega una breve reseña histórica sobre estos procesos.

$\mathrm{Al}$ momento de la llegada de los españoles la superficie de bosques nativo se estimaron que comprendían unos 25 a 28 millones de hectáreas, que fue la época probablemente de mayor superficie de bosques nativos. Pero desde la independencia del país y con los inicios de la colonización en el sur, se destruyeron casi las dos terceras partes de sus bosques nativos existentes, en un oscuro proceso de destrucción, incendios y habilitación de terrenos para la agricultura (Altamirano \& Lara, 2010; Lara et al., 2012). Hoy existe en el país una superficie de 13,6 millones hectáreas según el último catastro de bosque nativo realizado por Conaf, lo que se asemeja a lo catastrado en la Comisión Haig de 1945.

Los habitantes de la época colonial, la explotación de la minería y sus fundiciones destruyeron buena parte de los bosques en la zona central. Más tarde, los colonos Alemanes en el sur, destruyeron en forma sistemática la mayor cantidad de bosques para abrir espacio a actividades económicamente rentables, como las agrícolas y ganaderas, en las zonas entre las regiones del Maule y de Los Lagos. Había que asentarse y desarrollar infraestructura y actividades económicas, por lo que hacer desaparecer el bosque era algo considerado natural e inevitable (Donoso \& Otero, 2005).

Primero la colonización Alemana a mediados del siglo XIX entre Valdivia y Chiloé eliminó los bosques de roble, laurel, lingue y olivillo para transformarlos en terrenos de uso agrícola o ganadero. Luego, la acción de la colonización eliminó en casi su totalidad de los bosques de alerce del llano central en una extensa área entre el lago Llanquihue, Ensenada, Puerto Montt y el Océano Pacífico, dejando un terreno anegado e inútil para la actividad agropecuaria. Más tarde, durante la mal llamada pacificación de La Araucanía, entre los ríos 
Sustainability, Agri, Food and Environmental Research 3(2), 2015: 30-32 ISSN: 0719-3726

Biobío y Valdivia, Suizos, Italianos, Alemanes y Españoles destruyeron también los bosques nativos del llano central para habilitar terrenos agropecuarios (CIFAG,2013).

Por la gran magnitud que se le atribuía al bosque, y que a simple vista parecía infinito, se lo trataba como si fuera un recurso inagotable, y se lo cortaba a machetazos y con hachas, reduciéndolo con quemas que a veces duraban meses y arrasaban cientos de hectáreas (Lara et al., 2012). Durante la segunda mitad del siglo XIX y la primera del XX, la destrucción de bosques por incendios forestales, talas y quemas para habilitar terrenos cubrió gran parte de la región centro-sur de Chile entre ambas cordilleras, así como también los bosques mediterráneos de la región del Maule en ambas cordilleras, luego, durante la segunda mitad del siglo XX se produjo la destrucción por incendio de más de tres millones de hectáreas de bosques de lenga, coigüe común y coigüe de Magallanes en la región de Aysén, y enormes incendios forestales destruyeron grandes superficies de bosques de coigüe, raulí, tepa y araucaria en la Cordillera de los Andes, desde Malleco a Llanquihue”. (Adison \& Lara, 2005; Lara et al., 2012).

También hay una responsabilidad del sector forestal en sustituciones realizadas, las que se estiman cercanas 300.000 hectáreas (antecedentes recopilados según catastro forestal del año 1996 y diversos análisis basados en de los planes de manejo que Conaf realizó el año 2012), sin embargo, a partir de mayo del año 1998, se prohibió la sustitución de cualquier bosque nativo según la ley 19.561 (sobre la primera prórroga del instrumento de fomento forestal, en que se define lo que es bosque).

En el día de hoy se han identificado claramente los terrenos de aptitud forestal, los que están con escasa vegetación y muy degradados, en donde es posible realizar plantaciones forestales, lo que permite efectuar forestaciones en donde no existe presencia de bosque nativo, evitando de ese modo, la posible sustitución del bosque nativo. Por otra parte se ha impulsado el manejo del bosque nativo mediante la ley 20.283, del 5 de octubre del año 2009 de recuperación del bosque nativo y fomento forestal, que mediante incentivos, impulsa el adecuado manejo del bosque nativo.

\section{REFERENCIAS}

Altamirano, A. \& A. Lara, (2010). Deforestación en ecosistemas templados de la precordillera andina del centro-sur de Chile. Bosque 31(1): 53-64

Donoso, P.J. \& L.A. Otero, (2005). Hacia una definición de país forestal: ¿Dónde se sitúa Chile?. Bosque 26(3): 5-18. 
Sustainability, Agri, Food and Environmental Research 3(2), 2015: 30-32

Lara, A., M.E. Solari, M.R. Prieto \& M.P. Peña (2012). Reconstrucción de la cobertura de la vegetación y uso de suelo hacia 1550 y sus cambios a 2007 en la ecorregión de los bosques

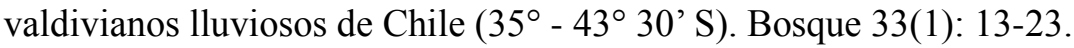

CONAF Catastro forestal del año 1996

CIFAG; El aporte de la Ingeniería Forestal al desarrollo del país 